\title{
Easing the transition of First Year Undergraduates Through an Immersive Induction
} Module

Rebecca Turner $^{1 *}$, David Morrison ${ }^{1}$, Debby $\operatorname{Cotton}^{1}$, Samantha Child ${ }^{2}$, Sebastian Stevens ${ }^{1}$, Patricia Nash ${ }^{1}$ \& Pauline Kneale ${ }^{1}$

Entry into higher education (HE) is recognised as a challenging time for undergraduates as they negotiate the norms and practices of new academic communities and foster relationships with peers and academics. Given the significance of this time period, our University has piloted a new four-week module that immerses students in their discipline and provides them with the academic skills and networks to support them through this period and beyond. Here we report a comprehensive evaluation examining academic and student experience of this immersive module. We explore its impact on essential aspects of the transition experience e.g. social integration, academic literacies and the sense of preparation for HE. Whilst this new approach did have positive impacts on students' sense of integration, questions were raised around the extent to which it matched or even raised expectations, and the extent to which this prepared students for the rest of their studies.

Keywords: Widening Participation, Student Experience, Induction, Retention, Study Skills

\section{Introduction}

Student retention has been a significant issue since the 1970s, with reasons for student withdrawal from university changing very little over this time period (Tinto 1975; Thomas 2012). However, there have been substantial changes in the profile of the undergraduate population, HE fee structures and government expectations of universities which have focused the attention of policymakers and university managers more firmly on factors determining student retention and success (Merill and Johnston 2011). Student transition into university is a key risk point for withdrawal, and successful transition entails students developing a sense of academic and social belonging (Tinto 1975; Thomas 2012), selfefficacy (Bandura 1977) and positive attributions (Bean 1980) to the university community. These factors are in turn influenced by prior experiences, a sense of preparedness for university-level study, and beliefs about knowledge and learning (Schommer-Aikins 2004; Hofer 2004; Thomas 2012).

Here we present a cross-institutional curriculum innovation designed to improve transition and retention at a UK University. The initiative seeks to immerse first year students in their 
programmes via a new stand-alone four-week immersive module. The immersive format was designed to allow students to experience only one module, which created dedicated time for the use of student-centred learning activities, and reduces the cognitive load placed on students in their early days at University. The modules were intended to 'immerse' students in their programme by introducing them to both the essential study skills relevant to HE-level study and relevant the theory, practice and language associated with their discipline. In addition students were required to complete formative and summative assessments within the module, therefore providing them with feedback on their progress within their first weeks at university and, ultimately, establishing expectations of the requirements for HE-level study. The development of an immersive format echoes innovations in America where some institutions have adopted 'immersive scheduling' to address concerns surrounding scheduling and retention from the mid-1990s (Davies, 2006; Muraskin, 1998). Concerns regarding student retention and their sense of preparation for HE-level study stimulated the curriculum innovation reported here. In this paper, we examine the student experience during and after this module and compare it to the experiences of students not in the pilot programmes via a mixed-method study. We conclude by evaluating the strengths and weaknesses of the immersive approach, as well as providing recommendations to direct future work in this area.

\section{Student retention and withdrawal in contemporary $\mathrm{HE}$}

A number of issues have been identified as helping with the transition to university. Karademas and Kalantzi-Aziz (2004) and Chemers et al. (2001) highlight the critical role of self-efficacy as it reduces stress by allowing students to view a 'threat' as a 'challenge', thus giving students a sense of control over a situation. Self-efficacy is linked to attribution theory, and depends on a student's ability to perceive and reflect on progress, attributing success to controllable factors (Bean 1980). Bandura (1977) found that setting realistic, short-term goals is essential as this promotes perseverance and improved effort. Self-efficacy can be promoted through social persuasion, self-evaluation and reflection, enactive mastery experiences and observation of others (Bovill et al. 2008). The strongest gains come from actual experiences of success at challenging tasks over time.

The social aspect of attribution, i.e. attribution given to students by others, is another influential factor (Weiner 2000). Positive social attributions can enhance personal selfefficacy, as well as increasing the sense of belonging. Kallenback and Zaft (2004) discuss 
'attributional retraining' to teach students to make positive attributions, identifying this as a social process that takes place through engagement with lecturers and their peers. This in turn, involves four parts: instructor modelling, peer leader modelling, student successes over time and developing a sense of self-control over learning (Demetriou and Schmitz-Sciborski 2011). Feedback on progress is integral to this retraining, therefore student engagement with assessment and feedback early on in their studies is essential (Bovill, Bulley and Morss 2011).

Another critical factor in withdrawal is students feeling unaware of or unprepared for the skills needed to succeed (Christie et al. 2013; Thomas 2012). Time management, independent study skills, and academic literacies (e.g. numeracy, academic writing), as well as having accurate expectations of university-level study, have been shown to be essential to positive self-efficacy (Christie et al. 2013). Students often do not enter university possessing all these skills, yet lecturers expect them (van der Meer et al., 2010). Increasingly, this is mediated through active induction activities, which in most universities are an integral aspect of students' orientation (Thomas, 2012). Though studies have demonstrated that unless it is made explicit to students that they are developing these skills personally, many will instead attribute them to external factors such as lecturers or peer support (Cheng 2015).

Overall the causes of student withdrawal from HE are complex. Forsman et al. (2015) conducted a large network analysis of factors shown to impact withdrawal, and identified no overarching cause - which may help explain why so little progress in reducing rates of withdrawal has been made (Tinto 2004). All of the factors above are essential, but not necessarily at the same time or for all students. Taking action to promote self-efficacy alone, for example, appeared to benefit some, but was unlikely to substantially affect the overall picture.

Given the importance of a student's early days at university, effective induction represents a crucial timeframe within which students need to develop a positive sense of self-efficacy, connection to the academic, disciplinary and social communities and an awareness of university-level study. Examples of extended induction periods operating at the programme level have recorded benefits to social integration and increased readiness for study (Edward and Middleton 2002; Gaskin and Hall 2002). These examples represent a stepwise change in student induction from the dissemination of information to the proactive management of transition. Yet, despite the significance of induction to retention, innovations around student 
induction have been slow, with a number of barriers (e.g. class size, insufficient time to design or implement, fears of 'dumbing down') preventing progress (Bovil et al. 2008). In addition, there is little extant research which has attempted to link induction activities with student retention.

\section{Widening participation and first year transitions}

Prior learning and experience is a major factor in retention, with student concerns over mismatched expectations or a poor sense of preparedness underlying many instances of withdrawal, especially for non-traditional students (Thomas 2012). Non-traditional students are those under-represented in $\mathrm{HE}$ - and whose participation may be limited by structural factors. They include first generation students, mature students, disabled students, single parents, students from low income families, and minority ethnic groups (Crosling et al. 2008). It is not necessarily the case that students who withdraw have experienced more difficulties than those who remain (Gilardi and Guglielmetti 2011), but there is evidence that nontraditional students are at particular risk (Merrill and Johnston 2011). Whilst there are individual variables (e.g. entry qualifications and personal background) which impact on retention, these are factors institutions cannot influence (Wolter et al. 2014). Therefore, for students from widening participation backgrounds an effective induction may be essential for easing the transition to university (Merrill and Johnston 2011). However, given the complexity of issues relating to student withdrawal, it is likely that induction will benefit all students, not just those from non-traditional backgrounds (Thomas 2012). Indeed, this resonates with Tinto's (2004) recommendation of an institutional approach to student induction, where all students receive the same contextualised support within the subjects.

\section{The curriculum innovation context}

The University which implemented this approach to the induction of first year students is a large institution with a long history of teaching innovation. It is recognised as diverse; it has a higher than average number of students from widening participation backgrounds. In 201314 93.9\% of the student body come from state schools, with $29.7 \%$ of first years originating from lower socio-economic backgrounds (Plymouth University 2013-14). Likewise 12.6\% of the total full-time undergraduate population have a declared disability - this is against a sector benchmark of 5.8\%. Of this 12.6\%, 9.3\% are in receipt of Disabled Students Allowance (Plymouth University 2013-14). Concerns around growing expectations for a high quality 
student experience, as well as the changing financial climate in the UK, has led to a renewed focus on the first year experience, specifically the support new students receive to promote their integration into academic communities and to develop skills integral to their academic success.

In 2014 a new model of semester-based curriculum design was piloted across 19 first year programmes (hereafter the early adopter group), with plans for whole institutional roll out in the 2015-16 academic year. One major change involved all first years studying only one module for their first four weeks at University, within which they would complete and receive feedback on module assessments. Although the specific content of each module would vary according to disciplinary perspectives, it would introduce students to universitylevel study and involve the use of active pedagogies that would encourage student-led learning. It was recommended that all taught sessions would be a minimum of two-hours in length to support pedagogic innovation. Assessments would be inclusive and exams would not be used - and there was a strong emphasis placed on formative assessment practices. Following completion of the immersive module, students complete two further modules running in parallel in the first semester.

This paper focuses on the immersive module, drawing on the lessons learned for students and staff through an evaluation study focused on this early adopter group. This study was designed to address the following research questions:

1. In what ways and to what extent does the immersive module support students to develop peer networks and relationships with academic staff?

2. To what extent did the immersive modules serve to prepare students for HE-level study through their implicit focus on study skills?

3. How did students negotiate the transition from the immersive module into a standard curriculum structure?

\section{Research design}

The evaluation was designed to capture data from multiple sources and perspectives, initially during the implementation of the immersive module, and subsequently towards the end of the academic year. It embraced the principles of Bamber (2013) who cites the need to 'evidence value' when evaluating curriculum innovation work. This can be achieved by drawing on 
measures of hard and soft outcomes (e.g. qualitative and quantitative measures of impact) to ensure insights are gained which are cognisant of context (Bamber 2013).

The first phase of the evaluation was broadly ethnographic in design; two research assistants gained first hand experiences of two immersive modules using participant observation. According to Pink (2007: 22) ethnography is a process of 'creating and representing data' that could provide authentic, contextualised and in-depth insights not easily obtained from other methods of data collection. Ethnography could embrace the subjective and complex nature of curriculum innovation, academics' responses and student engagement with these changes. The researchers attended all taught sessions associated with the modules, sitting amongst the students as they engaged with their studies. This allowed rapport to develop between the students, academic staff and the researchers, and resulted in the researchers adopting different roles and identities, a recognised strength of ethnographic studies (Pole and Morrison 2003). The researchers made field notes, supported by a semi-structured observation protocol prompting data collection on the pedagogic approaches used and levels of student engagement. This allowed them to build up 'thick descriptions' (Geertz 1973) of the dynamic of the teaching environment. The highly situated nature of the field notes was an acknowledged limitation of the observational methods (Emerson et al. 1995), thus semistructured interviews were held with staff involved in the design and delivery of each immersive module and student focus groups following completion of the modules. This allowed the researchers to clarify and explore further themes resulting from the ethnography. Additional data were obtained from a review of the student module evaluations in the programme for which these were available (Table 1).

Following the end of the immersive module an online survey was administered to all first year students to capture first year students' 'first impressions' of university life. The survey asked a series of questions regarding students' expectations of university, early experiences of teaching, learning and assessment, and included several measures of factors such as belonging and withdrawal. By distributing the survey to all first years, it provided the potential for comparisons to be made across respondents drawn from the curriculum innovation 'early adopter' group to those on the 'standard model' of curriculum design. The survey was open for four weeks following the end of the immersive module and used strategies recommended by Nulty (2008) to promote participation (e.g. reminder emails, small incentives and publicity). In total 789 useable responses were received representing a 
$12 \%$ response rate across the first year population. Of this $12 \%, 28.5 \%$ of respondents were drawn from the 'early adopter' and 71.5\% from the 'standard model', representing response rates of 3.5\% and $8.7 \%$ respectively across the whole first year population. Whilst this response rate is relatively low, motivating students to respond to online surveys is notoriously difficult, as Nulty (2008) discusses. Descriptive statistics were used to review the survey data, calculated using SPSS, and associations were explored using a Chi-square test.

In using the survey data we have to acknowledge the potential implications of self-selection bias on these data due to a number of reasons. Firstly, the survey was administered online; differing response rates and demographic profiles of respondents have been observed in comparisons of paper-based and online surveys (Watt et al., 2002). Self-selection bias can also result from 'systematic differences between respondents and non-respondents' (Nulty, 2008: 308) in that those choose to respond to the survey can differ in terms of age, gender and social class to those who do not respond (Richardson, 2005). Studies of course evaluations have also demonstrated that there are differences in academic attainment and behaviours of those who respond to those who do not too course evaluations (Goyder, 1987). These limitations to the sampling strategy used need to be considered in the framing of the survey data, as they limit the extent to which the findings can be generalised to the wider first year population. Therefore we use these data to provide indicative comparisons to the qualitative work which draws on a range of data sources.

Towards the end of the academic year, six focus groups were arranged with first year students from the pilot group on programmes not included in the ethnographic work in order to provide a wider picture of activity across the early adopter group. Themes from the initial work informed discussions and students were prompted to reflect on their experiences of the academic year holistically.

\section{Case study modules}

19 undergraduate programmes adopted the new model of curriculum delivery, representing programmes from across the Faculties of Health, Humanities and Business. Following a review of these programmes and their immersive modules, two were selected for inclusion in the evaluation, one from the Faculty of Health and the second from the Faculty of Business. They were contrasting programmes, and not solely from the disciplinary perspective. The Health module was delivered to a large cohort drawn from three degree programmes. The 
cohort was diverse including 'traditional' university students as well as those returning to education or with non-standard entry profiles. The Business module was focused on one, modest sized degree programme. These students were mostly 'traditional', young, first year students. Both immersive modules followed the same design principles, but the interpretation of these principles, resulting pedagogic innovations and student experiences varied greatly.

Table 1: Summary of data sources used in phase one

\begin{tabular}{|l|c|c|c|c|}
\hline Data source & Business & $\begin{array}{c}\text { Data source } \\
\text { Identifiers }\end{array}$ & Health & $\begin{array}{c}\text { Data source } \\
\text { Identifiers }\end{array}$ \\
\hline Ethnographic observations & 14 & BFN & 26 & HFN \\
\hline Student focus groups & 1 & BSFG & 2 & HSFG1/HSFG2 \\
\hline Staff interviews & 1 & BSIV & 5 & HSIV\# \\
\hline $\begin{array}{l}\text { Module evaluations } \\
\text { questionnaires }\end{array}$ & 53 & BSME & 0 & N/A \\
\hline
\end{tabular}

\section{Findings}

Analysis of the multiple data sources over the academic year highlighted number of key themes that offered valuable insights into the experiences of first year students on the immersive modules, which have been categorised into the following areas:

1) Belonging and social self-efficacy;

2) Study skills and academic self-efficacy;

3) Managing students expectations;

4) Inclusive assessment; and

5) Meeting expectations or moving goal posts

\section{Belonging and Social Self-efficacy}

Supporting students to achieve social integration was a key concern of the teaching teams, and a number of strategies were adopted to accomplish this:

"I've been doing things like encouraging them to form study groups, just to support each other around that and maybe they could continue that with their 
modules. And I think that has been a real strength and it's been something I've really enjoyed watching how they've started to form those relationships, and feel more confident and express less fear over time." (HSIV\#4)

To promote lasting cohort unity module leaders used team-building exercises in the first few days of both modules.

'We'd got to know each other, we'd broken the barriers [... ] It made us feel more comfortable around each other' (HSFG\#2)

"You're happy to sit with anybody because we all know each other and we're all friends, and there isn't a feeling of, you know, 'I don't want to sit with them.' ... I think that has come from those exercises and the way that the module was put together." (HSFG\#1)

In the Business module team building was integral to prepare students for subsequent group work as this was the dominant pedagogy, supported by field days and some individual student-led tasks. Students reported valuing the group work, describing it as an enjoyable and supportive way to undertake their first module:

"Really enjoyable module with a good mix of group work and individual work, lecture and workshop based activities" (BSME)

"Working in groups enabled us to discuss our worries about the assessment" (BSFG)

"I most enjoyed working as part of a team. Trying to get my point across in a working environment” (BSME)

The positive responses to working with peers suggests that students perceived it as meaningful and valuable - this is essential for promoting a sense of belonging and engagement to the academic community (Kuh et al. 2008). 
The focus placed on networking through the use of pedagogies that promote peer interaction, and the immersive nature of the module itself, had positive effects across the whole early adopter group. This trend was indicated by respondents to the 'first impressions' survey, who tended to identify the level of peer interaction as 'yes, about right,' by 7 percentage points, though this was not identified as a statistically significant relationship through subsequent analysis (Table 2).

Table 2: Level of peer interaction with other students

\begin{tabular}{|l|c|c|c|}
\hline Group & Yes, about right & No, too little & No too much \\
\hline $\begin{array}{l}\text { Early Adopter } \\
\text { (n=191) }\end{array}$ & $86.9 \%$ & $12.0 \%$ & $1.0 \%$ \\
\hline $\begin{array}{l}\text { Standard Model } \\
\text { (n=478) }\end{array}$ & $80.3 \%$ & $16.3 \%$ & $3.3 \%$ \\
\hline
\end{tabular}

A common concern for new university students is the accessibility and approachability of academic staff, as there is the widely held perception that academics will have little time and students will be anonymous (Thomas 2012). Indeed Chickering and Gamson (1987) highlight student-staff contact within their seminal guidance on effective practices in undergraduate teaching. However, this was a concern that was not realised amongst the early adopter programmes. Students also reported positive experiences of interactions with academic staff. In both modules, students talked about feeling able to approach staff, getting to know them, and feeling like they were supported in their learning.

"[names tutor] not intimidating either, because, you know, sometimes you see a teacher and you think, 'Oh, I can't ask them that.' But they are so lovely you can just ask them whatever you want." (HSGF\#1)

This was echoed across the first impressions data, and supported by a statistically significant relationship: $X^{2}(4)=9.38, p=0.05$ ) (Table 3):

Table 3: Expectations of the level of academic support that would be available

\begin{tabular}{|l|c|c|c|}
\hline Group & Combined high* & About right & Combined low* \\
\hline $\begin{array}{l}\text { Early Adopter } \\
\text { (n=188) }\end{array}$ & $16.0 \%$ & $62.8 \%$ & $21.3 \%$ \\
\hline Standard Model & $25.0 \%$ & $56.3 \%$ & $18.7 \%$ \\
\hline
\end{tabular}


$(n=476)$

* A five point Likert scale was used for this question covering the following categories: 'much too high', 'a bit too high', 'about right', 'a bit too low' and 'much to low'. The 'high' and 'low' categories were collapsed for reporting purposes

\section{Study Skills and Academic Self-efficacy}

Developing students study skills and academic literacies were also core aims of the immersive modules. In designing the Health module, the team responded to concerns from previous cohorts who felt that they were ill prepared for higher-level study. Prior student performance was used to identify where study skills were most needed, including reflective writing, critical thinking, numeracy, and literature searching. The module leaders prioritised these in their immersive module. They brought in study skills specialists from central support teams to lead these sessions, with disciplinary specialists following up the themes introduced in subsequent seminars. To prompt the timely practice of these skills, formative and summative assessments were implemented early on, often using peer assessment in seminars to facilitate discussion and reflection.

Although this approach would adhere to good practice in the literature (e.g. Cotterell 2001; Wingate 2006), in that it sought to build connections between generic skills and disciplinary knowledge, in practice, the response of students to these sessions was mixed. The Health students, in particular, felt too much emphasis was placed on some topics and questioned the relevance or timing of sessions:

"I did enjoy these, but they could have been shortened [...] it was nice to see the level of support you get here so that I did like, but again, condensed maybe." (HSFG\#2)

"There was one lecture that was how to interpret an essay question and I was like, I've been writing essays constantly for the last however long. But then there are people who have been out of education for years who would need to do it. I think there were a lot of things that were a bit pointless for people, do you know what I mean, and it should have been optional." (HSFG\#1) 
Students recognised the need for some support in developing essential study skills, but suggested they should be able to self-determine their engagement. This is a problematic solution, as it could be perceived as a 'deficit' approach to study skills. Indeed, often those that need support are not aware of their own developmental requirements at this early stage (Wingate 2006). Several studies (e.g. Cook \& Leckey, 1999; Goldfinch \& Hughes, 2007) have demonstrated that not only do some first year students enter university with an unfounded sense of confidence in their abilities in essential study skills, they are also not aware of the need to modify their study habits to accommodate the change level they are now working at (Lowe \& Cook, 2003). Therefore, reflecting on the position of these students and also the findings of these studies, an inclusive approach to essential study skills is appropriate. In delivering these sessions lecturers should consider incorporating activities that challenge or disrupt students' current knowledge, leading them to questioning their abilities and recognising value in these study skills sessions. Though this would require careful framing to avoid undermining the confidence of students who are less certain in their abilities, these risks could be mediate through further use of active learning and group-based activities that allow students to realise that are all starting from a similar position (Thomas, 2012). Such strategies could further reinforce peer networking and sense cohort identity already resulting from the immersive format of the module.

The main concern for Health students, however, was the decontextualized nature of these sessions. Despite efforts to contextualise the skills in the seminar after, lecturers were not involved in delivery of the main content:

"It would be nice to be taught by [an expert] who understands the relevance to [subject]" (HSFG\#2)

Consequently, students perceived these sessions to have limited relevance to their studies, and this could potentially impact the extent to which they attended optional sessions available centrally. Indeed, the researcher observed that when students needed guidance they turned to the discipline-based lecturers rather than study skill specialists for support. The relationships noted in the previous section made students feel that they were in a position to do this, potentially mitigating any risks to students emerging sense of academic self-efficacy as they 
had a source of support. However, the original intention of equipping students with essential study skills through taught sessions does not seem to have been fully realised.

In contrast, the Business module integrated study skills directly into the teaching, learning and assessment of the module, with the subject specialist delivering the academic and study skills content in a holistic fashion. This does resonate more explicitly with approach advocated in the literature (e.g. Durkin and Main 2002; Wingate 2006) than that taken by the Health team. The module was delivered through a series of workshops which involved lecturer-led and student-led activities, with students working on a live project for an outside employer. Through these different activities they were required to develop an understanding of, and gain practice in, skills such as reflective writing and critical appraisal, which they engaged with through the lens of the discipline. The success of this approach was evidenced by the absence of any concerns about study skills in the field notes and the subsequent focus group. Students did not voice concerns about irrelevant sessions or skills, and strong student performance and overall satisfaction suggested that the students developed the required skills.

\section{Managing students' expectations of the immersive module}

The immersive module was intense: 20 credits of level four study were condensed into four weeks. The curriculum innovation created the potential to move away from content-focused, didactic lectures to problem-based or active learning, where the emphasis was on experimentation and self-discovery. This represents a considerable change from how most students are taught, and therefore there was a clear need for module teams to manage student expectations around this first module, and how they reconcile this with their expectations of HE-level study. Course teams developed their modules drawing on institutional design guidelines, but also addressed specific concerns particular to their students (e.g. social integration, study skills). The extent to which lecturers effectively managed student expectations of the immersive module were variable, as evidenced from student reflections on the Business module and respondents to the survey. Overall a higher percentage of those responding to the survey in the early adopter group reported 'inaccurate' expectations compared to those in the 'standard model' who tended to report more 'accurate' expectations (Table 4). These inaccuracies in expectations across the two groups of respondents were supported statistically: $X^{2}(3)=9.65 p=0.02$. This could be taken to represent a mismatch in expectations of how modules would be taught and how students were expected to learn across 
by those responding to this survey for those in the early adopter group compared to those in the standard model, which was predominately lecture based.

Table 4: Student expectations of teaching methods that would be used

\begin{tabular}{|l|c|c|c|c|}
\hline Group & $\begin{array}{c}\text { Very } \\
\text { accurate }\end{array}$ & $\begin{array}{c}\text { Quite } \\
\text { Accurate }\end{array}$ & $\begin{array}{c}\text { Quite } \\
\text { Inaccurate }\end{array}$ & $\begin{array}{c}\text { Very } \\
\text { Inaccurate }\end{array}$ \\
\hline $\begin{array}{l}\text { Early adopter } \\
\text { (n=188) }\end{array}$ & $8.5 \%$ & $64.4 \%$ & $23.4 \%$ & $3.7 \%$ \\
\hline $\begin{array}{l}\text { Standard model } \\
(\mathbf{n = 4 6 8 )}\end{array}$ & $14.1 \%$ & $68.2 \%$ & $15.0 \%$ & $2.8 \%$ \\
\hline
\end{tabular}

Mismatched expectations emerged as a potential issue from the ethnographic study of the Business module. In designing the module, the team prioritised student engagement.

Problem-based learning underpinned the module, with students working collaboratively on an employer-led problem which, along with the fieldtrips and social events, sought to promote peer networking. The lecturer sought to minimise didactic, teacher-led content, instead leading the module through a series of interactive workshops:

"I knew that I wanted engagement, which means I wanted people in the room. I also wanted it to be completely flipped so that the majority would be - or at least 50\% would be working on stuff, applying stuff, and no more than 50\%, but less than 50\% preferably, of input from the lecturer. " (BLIV)

The course team realized they had high expectation of students, particularly with respect to how they were expected to manage their time to effectively engage with the module. They sought to mediate this using a structured timetable which mapped out all teaching and learning activities including independent study (e.g. reading, assessed work), group work, workshops and other course related activities (e.g. field trips, social events). Students reported that this helped them understand clearly what was expected and when (in terms of effort required and deadlines), and helped give practical experience of 'good study skills' (BSFG). Conversely, students struggled to balance levels of lecturer-led and student-led contributions, particularly with respect to the time needed to grasp new concepts. This indicates the need for mechanisms to promote reflection on theoretical concepts and to 
develop students' confidence with the knowledge they are gaining. The students related these struggles to the need for more lecturer input:

\author{
"More theory in lectures before group work" (BSME) \\ "Students who do not have any business or finance background seem a long \\ way behind in today's session.” (BSFG)
}

Whilst the initial reaction of some lecturers may be to consider reverting to a traditional lecture-based model, it is probable that these concerns could be mitigated by dedicating time at the beginning of the module to discussing module delivery and student expectations. These discussions should include explanations of why specific teaching strategies are used and how students should engage with them in order to maximise their learning. It has been observed that many undergraduates employ strategies in their learning that "consume considerable time without leading to durable learning' or that students do not know how to effectively engage with tasks set by lecturers (Putnam et al. 2016: 652; Dunlosky et al., 2013). Actively engaging students in dialogue around teaching and learning, with attention paid to both the role of the 'student' and the 'lecturer', may promote deep learning as well as further stimulating the development of key study skills.

The immersive modules could take these discussions further as attention should not only be paid to students expectations for module delivery, but also for their own learning. A student's prior knowledge is recognised as an important predictor of student achievement and shaping their future learning, however, many students are unaware of their current knowledge and skill base (Hailikari et al 2008; Thompson \& Zamboanga 2003). Indeed, inadequate recognition of a student's knowledge and skill base can hamper future learning (Hailikari et al 2008). Therefore the extent to which the immersive module allows students to consider what they know and how well they know it should be further considered, as unless students become aware of their own starting points, they are unlikely to recognise the extent to which they are changing and developing through the module, and potential gains for self-efficacy could be missed (Booth 2001). Discussions focusing on module delivery and students existing knowledge and skills in their chosen programme did not occur in the pilot of the immersive format, however, attention has been paid in subsequent 
iterations to both engage students in a discussion regarding the pedagogy of the immersive modules and scaffolding student learning with a view to maximise their learning gains.

\section{Inclusive Assessment}

Inclusive assessment ensures all students have the opportunity to demonstrate the acquisition of knowledge and learning in a supportive yet challenging environment (Nichol 2009). Getting this balance right is integral to promoting the self-efficacy of students (Bandura 1977; Nichol 2009). Given the immediacy of the immersive module (in that students would be engaging in formative and summative assessments within four weeks of commencing university study), inclusive assessment was necessarily foregrounded in module design.

In both modules, formative and summative assessments were presented at the beginning of the module with weekly reminders; staff were explicit about the learning outcomes and assessment requirements, with further information in the module handbook. However, despite the efforts of the teaching teams to present assessment information coherently, this was not the experience of students, possibly simply because they were still unfamiliar with the norms and expectations of HE study. This raises an important point regarding clarity of assessments, which need to take account of the students' current perspectives, their level of knowledge and limited experience of HE assessment (Nichol 2009). This was exemplified within the Health module with respect to communication around the changing timeframe of assessment and feedback. Previously students might not receive any feedback until after Christmas, whereas in the new model assessment and feedback were earlier. However, these wider benefits were not foregrounded and thus may not have been appreciated by all the students. There was evidence of this effect in the focus group discussions: students did say that feedback helped them get a sense of how they were doing, but only after the researcher explained to them that this was not how it had been before. This examples indicates that at this early stage, students did not yet have the experience to maximise engagement in the assessment process; further support is needed to allow them to form connections in current and future learning (Booth 2001; Nichol 2009).

The change in assessment practices raised anxieties for the module teams, with concerns expressed about their ability to provide appropriate depth of feedback in the required 
timeframe. However, research suggests that detailed feedback is less valuable for both learning and student satisfaction than concise but expedient feedback (Nichol 2009). Indeed, given the need to promote students' effective engagement with the assessment process, too much detailed feedback may be counterproductive at this stage.

\section{Meeting Expectations or Moving the Goalposts?}

Evaluation of the immersive module at the time of delivery highlighted strengths with respect to peer networking and introducing university-level study and assessment practices. After the module however, students moved on to parallel modules which appeared to disrupt some of the newly-established social networks and academic development, raising concerns that the difficult transition to university-life had simply been delayed. Focus groups held towards the end of the academic year, with students from a range of other early adopter programmes, suggested that students still needed to transition into a different mode of study at some point.

The immersive module appears to have raised expectations with respect to the accessibility and contact with tutors and peers, and in this sense the design was very successful. However, this did not help students develop realistic expectations longer term. Integration of social or academic activities to promote peer networking did not continue after the first module. Likewise, consistency and closeness of tutors were not features of subsequent modules. Instead, students moved on to modules that divided social groupings and students were no longer with the lecturers they had built rapport with:

\footnotetext{
I don't really feel that connected to the person taking the seminar. I think the difference is that Mary was our tutor, whereas now we've got Ben and Sue who are just our lecturers (FG1)
}

Many also had to adjust to larger class sizes, differing methods of instruction and assessment.

It's not their fault because there's hundreds of us, compared to the [immersive] one where there's maybe 40, but I would say there's definitely a quality gap. (FG2)

What was comforting was knowing your personal tutor was actually marking, so you knew who to go to for the curriculum. Now you would talk to someone in a 
different seminar and they had got told something completely different, and then you'd ask the teacher, and then again next week it would change again. (FG1)

They were now studying two modules simultaneously and expected to cope with the demands this placed on their time management and study skills. Whilst these challenges were not insurmountable and students gradually adapted to the changing pace of their studies, they felt they could have been better prepared for this second transition from a supportive immersive module into a more traditional model of HE study.

\section{Conclusion}

This research presents an evaluation of a cross-institutional curriculum change project focused around student induction, intended to prepare students for the rigours of universitylevel study as well as promoting the development of supportive peer networks. Drawing on the principles of ethnography, this study was designed to capture students' and lecturers' experiences of the innovation as it was implemented. Through follow-up focus groups, insights were gained into the impact it had on their first year of university life.

Across both modules studied, the immersive format promoted the development of peer networks and helped students forge relationships with academic staff. These networks were stimulated by purposeful engagement with course-related activities and social events early in each module. They successfully challenged students' negative perceptions about the accessibility of academic staff and minimised the potential for social exclusion of new students. Evidently, in designing an immersive student induction, there is clear value in considering academic and social activities as part of the holistic student experience. These are mutually beneficial and reinforcing: social activities that promote networking between peers (and potentially also with academic staff) can allow students to get to know one another before they engage with academic work (Bovill, Bulley and Morss 2011). Likewise integrating pedagogies such as group work into student induction allows students to build quickly on these social bonds and become familiar with collaborative working early on in their academic life.

Study skills underpinned the design of each module, however, the approach taken to their delivery influenced student engagement and perceived relevance. Whilst these are common 
concerns regarding teaching study skills (Wingate 2002; Thomas 2012), getting the integration right at the earliest stage is crucial in providing the underpinning for subsequent HE study. Employing pedagogies that promote active engagement with learning and contextualising study skills in discipline-based activities is essential to avoid students dismissing such learning as irrelevant. Both situations were documented in this study; in one instance students were not aware of engaging with study skills, while in the other students rapidly disengaged. In both cases there may be benefit in taking time to consider specifically the skills developed in these formative weeks and how they support student engagement with future modules. Thus students can be made explicitly aware of the academic progress they are making, rather than recognising only what is ratified through assessment feedback.

A range of pedagogic approaches were used within each module with varying levels of success, which may partly reflect student expectations of what constitutes teaching and learning at University. It is recognised at this stage that most students have a conception of knowledge as fixed, and through their studies they become more comfortable and able to reconcile contested nature of knowledge (Hofer 2004; Schommer-Aikens 2006). The fixed conception of knowledge aligns with the more traditional forms of university teaching and learning - the lecture where the student is the novice and lecturer the expert (Schommer 1990). Approaches such as problem-based learning disrupt this traditional novice-expert relationship and place the control for learning with the student (Dochy et al. 2003). For new students, who are neither expecting nor prepared for these approaches to teaching and learning this can be an uncomfortable and challenging space for them to occupy (Pawson et al. 2006). This does not mean we should avoid such approaches since, in the long term, gaining a sense of the contested nature of knowledge early in their studies will benefit students' academic development. But support structures, fostered through collaborative working and peer networks, are required to help students recognise that they are not alone in experiencing these concerns (Pawson et al. 2006). Given the potential vulnerability of first year students, the use of such pedagogies should therefore be carefully structured and supported.

This curriculum innovation represented an ambitious move to address the complex issues that underpin student retention. Reflecting on the experiences of these students and staff with respect to the theoretical underpinnings of the retention literature demonstrates that progress has been made in some areas but not all. The innovation was successful in creating 
conditions through which students could develop a sense of social attribution and belonging through social and academic collaboration and interaction. Peer relationships may have played a significant role in mediating potential negative effects at times when academic challenge or mismatched expectations could have led to student disengagement or withdrawal. The need to manage student expectations is an aspect of the immersive module which was not fully realised at the time of implementation. Having made an initial module which was widely felt to be successful, the expectations for subsequent teaching were arguably difficult to live up to.

\section{Disclosure Statement}

There are no personal or institutional conflicts of interest to be disclosed.

\section{Acknowledgements}

The authors would like to thank the students and staff at the University of XXXX who participated in this study, which enabled us to gain valuable insights into a new model first year student induction.

\section{References}

Bamber, V. 2013. “A Desideratum of Evidencing Value.” In Evidencing the Value of Educational Development: 39-46, (ed.) Bamber, V: London, SEDA.

Bandura, A. 1977. "Self-efficacy: toward a unifying theory of behavioural change." Psychological Review 84 (2): 191-215.

Bean, J.P. 1980. "Dropouts and turnover: The synthesis and test of a causal model of student attrition." Research in Higher education 12(2): 155-187.

Booth, A. 2001. "Developing History Students' Skills in the Transition to University". Teaching in Higher Education, 6 (4): 487-503

Bovill, C., Bulley, C.J. and Morss, K. 2011. "Engaging and Empowering First-Year Students through Curriculum Design: Perspectives from the Literature.” Teaching in Higher Education 16(2): 197-209.

Bovill, C., Morss, K. \& Bulley, C. 2008. Quality Enhancement Themes: The First Year Experience: Curriculum Design for the First Year. Glasgow: Quality Assurance Agency Scotland.

Chemers, M.M., Hu, L.T. and Garcia, B.F., 2001. Academic self-efficacy and first year college student performance and adjustment. Journal of Educational psychology, 93(1): 55-64. 
Cheng, Ming. 2015. "Transition Skill Strategies: Transition Models and How Students Experience Change.” Quality Assurance Agency for Higher Education: Scotland.

Christie, H., Barron, P., and D'Annunzio-Green, N. 2013. "Direct entrants in transition: becoming independent learners". Studies in Higher Education, 38 (4): 623-637.

Cook, A. and Leckey, J. 1999. "Do expectations meet reality? A survey of changes in first year student opinions.” Journal of Further and Higher Education, 23(2): 157-171.

Cotteral, S. 2001. Teaching study skills and supporting learning. Basingstoke: Palgrave.

Crosling, G., Thomas, L. and Heagney, M., 2008. Improving student retention in higher education: the role of teaching and learning. Routledge.

Davies, W.M. 2006. "Intensive teaching formats: a review." Issues in Educational Research, 16(1): 1-20.

Demetriou, C., and Schmitz-Sciborski., A. 2011. "Integration, motivation, strengths and optimism: Retention theories past, present and future." In R. Hayes (ed.), Proceedings of the 7th National Symposium on Student Retention: 300-312. Norman OK, University of Oklahoma.

Dochy, F., Segers, M., Van den Bossche, P. \& Gijbels, D. 2003. Effects of problem-based learning: a meta-analysis. Learning and Instruction 13(5), 533-568.

Durkin, K. \& Main, A. 2002. Discipline-based study skills support for first year undergraduate students. Active Learning in Higher Education 3(1): 24-39.

Edward, N.S. and Middleton, J. 2002. The challenge of induction! Introducing engineering students to higher education: a task-oriented approach, Innovations in Education and Teaching International 39 (1): 46-53.

Emerson, R. M., Fretz, R. I., and Shaw, L. L. 1995. Fieldnotes in ethnographic research.

Forsman, J., 2015. Complexity Theory and Physics Education Research: The Case of Student Retention in Physics and Related Degree Programmes. Digital Comprehensive Summaries of Uppsala Dissertations from the Faculty of Science and Technology 1273. University of Uppsala: Sweden. Available from: https://uu.divaportal.org/smash/get/diva2:846064/FULLTEXT01.pdf

Gaskin, S. and Hall, R., 2002. Exploring London: a novel induction exercise for the new undergraduate. Journal of Geography in Higher Education 26(2): 197-208. 
Geertz, C. 1973. The Interpretation of Cultures: Selected essays. New York, Basic Books.

Gilardi, S. and Guglielmetti, C., 2011. University life of non-traditional students: Engagement styles and impact on attrition. The Journal of Higher Education, 82(1): 33-53.

Goldfinch, J. and Hughes, M. 2007. "Skills, learning styles and success of first-year undergraduates”. Active Learning in Higher Education 8(3): 259-273.

Goyder, J. 1987. The silent majority: non-respondents on sample surveys. Cambridge: Polity Press.

Hailikari, T., Katajavuori, N. and Lindblom-Ylanne, S. 2008. The relevance of prior knowledge in learning and instructional design. American Journal of Pharmaceutical Education 72(5): 1-8.

Hofer, B. K. 2004. "Exploring the Dimensions of Personal Epistemology in Differing Classroom Contexts: Student Interpretations during the First Year of College." Contemporary Educational Psychology 29(2): 129-63.

Kallenbach, S., and Zafft, C. 2004. "Attributional retraining: Rethinking academic failure to promote success." National College Transition Network: Research to Practice 1: 1-3.

Karademas, E.C. and Kalantzi-Azizi, A., 2004. The stress process, self-efficacy expectations, and psychological health. Personality and individual differences, 37(5): 1033-1043.

Kuh, G.D., Cruce, T.M., Shoup, R., Kinzie, J. and Gonyea, R.M., 2008. Unmasking the effects of student engagement on first-year college grades and persistence. The Journal of Higher Education 79(5): 540-563.

Lowe, H. and Cook, A. (2003). "Mind the gap: are students prepared for higher education?" Journal of Further and Higher education 27(1): 53-76.

Merrill, B. \& Johnston, R. 2011. Access and retention: experiences of non-traditional learners in HE. Available online at: http://www.dsw.edu.pl/fileadmin/wwwranlhe/files/Literature_Review_upd.pdf

Muraskin, L.D. 1998. A structured freshman year for at-risk students. US Department of Education, Washing, DC

Nicol, D. 2009. "Assessment for Learner Self-regulation: Enhancing Achievement in the First Year Using Learning Technologies.” Assessment \& Evaluation in Higher Education 34(3): 335-52. 
Nulty, D.D. 2008. The adequacy of response rates to online and paper surveys: what can be done? Assessment and Evaluation in Higher Education 33(3): 301-314.

Pawson, E., Fournier, E., Haigh, M., Muniz, O., Trafford, J. \& Vajoczki, S. 2006. Problembased learning in Geography: towards a critical assessment of its purposes, benefits and risks. Journal of Geography in Higher Education, 30(1): 103-116.

Pink, S. 2007. Doing Visual Ethnography. London: Sage.

Plymouth University. 2013. Plymouth University's Access Agreements 2013-14. Accessed from https://www.offa.org.uk/agreements/University\%20of\%20Plymouth\%200073\%20access\% 20agreement\%202013-14.pdf $15^{\text {th }}$ January 2016.

Pole, C. and Morrison, M. 2003. Ethnography for Education. Maidenhead: Open University Press.

Richardson, J.T.E. 2005. "Instruments for obtaining students feedback: a review of the literature." Assessment \& Evaluation in Higher Education 30(4): 387-415.

Schommer-Aikins, M. 2004. "Explaining the Epistemological Belief System: Introducing the Embedded Systemic Model and Coordinated Research Approach.” Educational Psychologist 39(1): 19-29.

Schommer, M. 1990. "Effects of Belief About the Nature of Knowledge Comprehension." Journal of Educational Psychology 82 (3): 498-504.

Thomas, L. 2012. Building student engagement and belonging in higher education at a time of change: final report from the 'what works?' student retention and success programme. Accessed

Thompson, R.A. and Zamboanga, B.L. 2003. "Prior knowledge and its relevance to student achievement in introduction to psychology." Teaching of Psychology 30(2): 96-101.

Tinto, V. 1975. "Dropout from higher education: A theoretical synthesis of recent research." Review of educational research, 45: 89-125.

Tinto, V. 2004 "Student Retention and Graduation: Facing the Truth, Living with the Consequences. Occasional Paper 1." Pell Institute for the Study of Opportunity in Higher Education. 
Watt, S., Simpson, C., McKillop, C., and Nunn, V. 2002. "Electronic course surveys: does automating feedback and reporting give better results?" Assessment \& Evaluation in Higher Education 27(4): 325-337.

Weiner, B. 2000. "Attributional thoughts about consumer behaviour." Journal of Consumer research 27, (3): 382-387.

Wingate, U. 2006. Doing away with 'study skills'. Teaching in Higher Education 11(4): 457469.

Wolter, S.C., Diem, A. \& Messer, D. 2014. Drop-outs from Swiss universities: an empirical analysis of data on all students between 1975 and 2008. European Journal of Education 46(4): 471-483. 